\title{
Endoscopic submucosal dissection with early multitraction placed before circumferential incision allows excellent exposure but with a risk of catching the muscularis propria
}

Traction-assisted endoscopic submucosal dissection (ESD) is very effective and is becoming standard for colorectal ESD [1]. Recently, we developed the multitraction strategy to increase traction power in difficult lesions [2]. In order to benefit from the maximum potential of this technique, both to make the resection technically easier and to save time on the procedure, it seemed interesting to try to place the traction as early as possible to take advantage of the exposure power earlier.

We report here on a 91-year-old man with a large granular laterally spreading tumor of the upper rectum. The multitraction strategy was put in place early before the circumferential incision was performed and offered excellent submucosal exposure ( Fig. 1 ; Video 1 ). The initial incision under traction resulted in a deep groove, allowing incision and trimming to be performed at the same time. We made punctate incisions at the four cardinal points after injection in order to anchor the clip in the submucosa and not in the muscularis propria. However, although three of the clips were placed on the submucosa without any fixation of the muscularis propria, the last clip accidentally caught the muscularis despite the prior injection. This made the dissection more difficult and led to thermal damage of the lesion by diffusion of electric current to the clip during the dissection phase.

Optimization of this early multitraction technique, by making short linear incisions at the four cardinal points before placing the clips, was performed in a second patient, a 71-year-old woman with a granular laterally spreading tumor of the sigmoid colon ( $>$ Fig. 2 ; $>$ Video 1 ). This made it possible to avoid the risk of placing the clips in the muscularis while
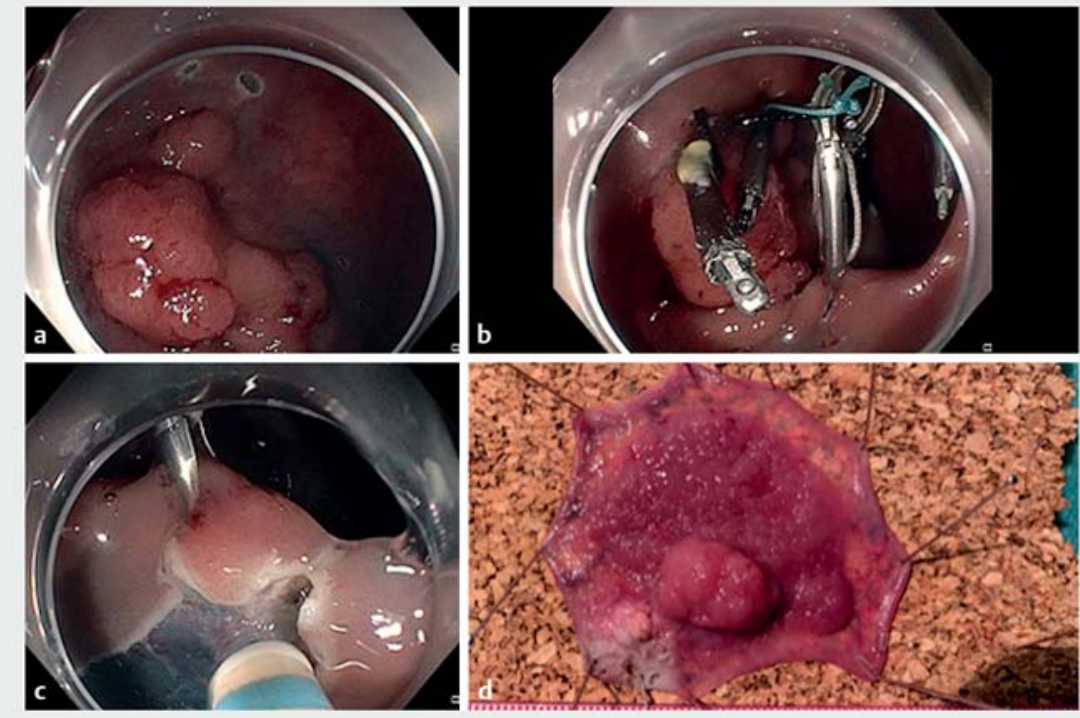

- Fig. 1 Granular laterally spreading tumor (LST-G) in a 91-year-old man, resected by endoscopic submucosal dissection (ESD) with early multitraction placed in punctate incisions at the four cardinal points. a Punctate incisions at the four cardinal points to anchor the clips. b Overview after placing of the multitraction. c Beginning of circumferential incision; a deep groove is obtained. $\mathbf{d}$ Lesion stretched on cork.
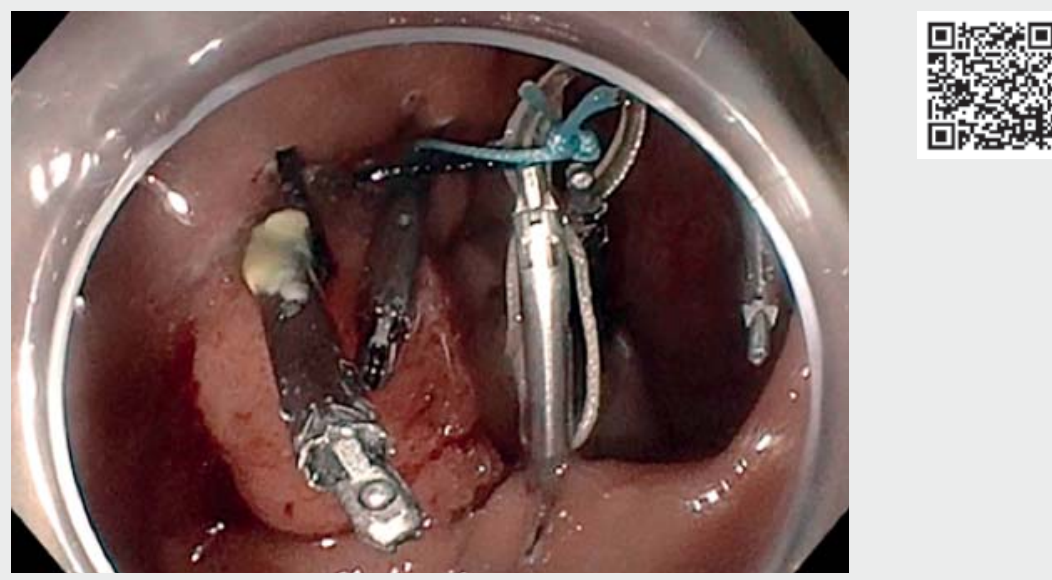

Video 1 Endoscopic submucosal dissection with early multitraction strategy placed before the circumferential incision is carried out: presentation of two cases. 

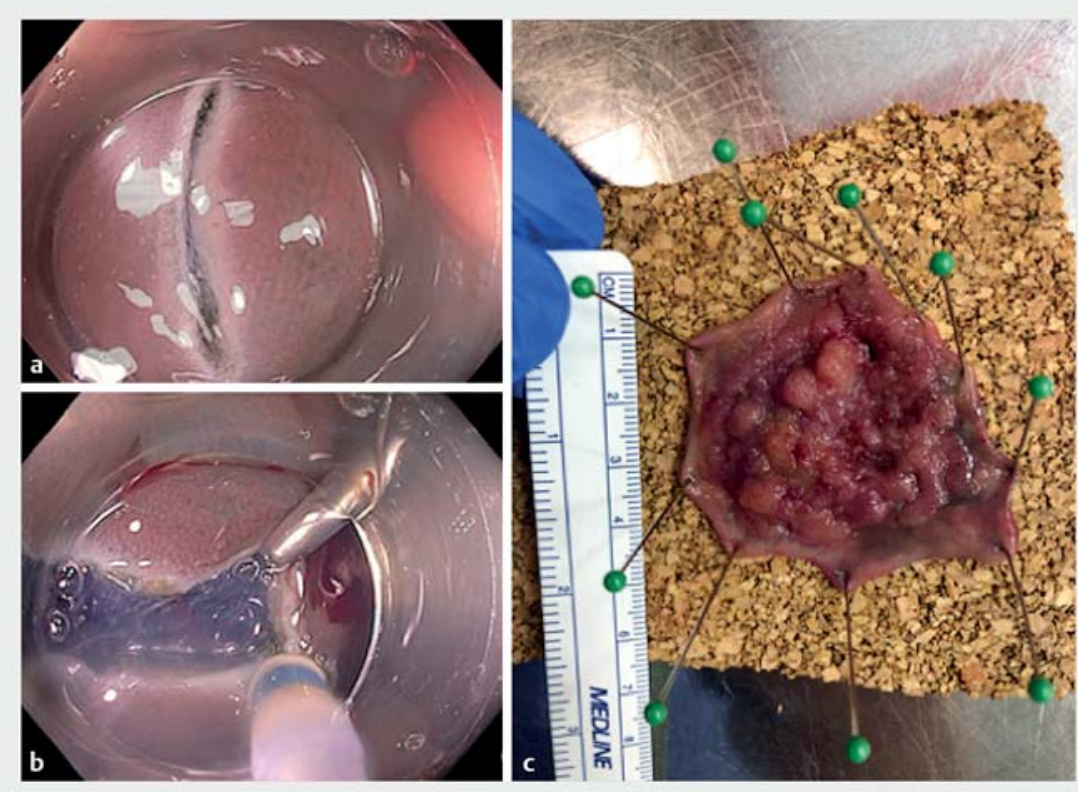

Fig. 2 Granular laterally spreading tumor (LST-G) in a 71-year-old woman resected by ESD with early multitraction placed in short linear incisions at the four cardinal points. a Short linear incision to allow safe placement of the clip. $\mathbf{b}$ Clip placed on the edge of the incision to avoid catching the muscularis propria. c Lesion stretched on cork.

saving time in the initial incision phase, which seems more effective with initial traction. Further evaluation is needed to determine the optimal time for traction placement.

Endoscopy_UCTN_Code_CPL_1AJ_2AD

\section{Competing interests}

The authors declare that they have no conflict of interest.
The authors

Jean Grimaldi ${ }^{1}$, Jérôme Rivory ${ }^{1}$, Thomas Lambin ${ }^{1}$, Pierre Lafeuille ${ }^{1}$, Jérémie Jacques ${ }^{2}$, Thierry Ponchon ${ }^{1}$, Mathieu Pioche ${ }^{1}$

1 Endoscopy and Gastroenterology Unit, Edouard Herriot Hospital, Hospices Civils de Lyon, Lyon, France

2 Gastroenterology and Endoscopy Unit, Dupuytren University Hospital, Limoges, France

\section{Corresponding author}

\section{Mathieu Pioche, MD}

Endoscopy Unit, Department of Digestive Diseases, Pavillon L - Edouard Herriot Hospital, 69437 Lyon Cedex, France mathieu.pioche@chu-lyon.fr

\section{References}

[1] Bordillon P, Pioche M, Wallenhorst T et al. Double-clip traction for colonic endoscopic submucosal dissection: a multicenter study of 599 consecutive cases (with video). Gastrointest Endosc 2021; 94: 333-343

[2] Lafeuille P, Rivory J, Jacques J et al. Diagnostic endoscopic submucosal dissection for invasive cancer with the four cardinal points traction strategy. Endoscopy 2021. doi:10.1055/a-1516-3680

\section{Bibliography}

Endoscopy 2022; 54: E510-E511

DOI 10.1055/a-1655-8226

ISSN 0013-726X

published online 15.10 .2021

(c) 2021. Thieme. All rights reserved.

Georg Thieme Verlag KG, Rüdigerstraße 14,

70469 Stuttgart, Germany

\section{ENDOSCOPY E-VIDEOS}

https://eref.thieme.de/e-videos

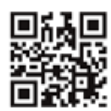

Endoscopy E-Videos is an open access online section, reporting on interesting cases and new techniques in gastroenterological endoscopy. All papers include a high quality video and all contributions are freely accessible online. Processing charges apply (currently EUR 375), discounts and wavers acc. to HINARI are available.

This section has its own submission website at https://mc.manuscriptcentral.com/e-videos 